\title{
Intoxicação experimental por Phalaris angusta (Gramineae) em bovinos ${ }^{1}$
}

\author{
Renato Silva de Sousa ${ }^{2}$ e Luiz Francisco Irigoyen ${ }^{3}$
}

\begin{abstract}
Sousa R.S. \& Irigoyen L.F. 1999. [Experimental poisoning by Phalaris angusta (Gramineae) in cattle.] Intoxicação experimental por Phalaris angusta (Gramineae) em bovinos. Pesquisa Veterinária Brasileira 19(3/4):116-122. Depto Patologia, Universidade Federal de Santa Maria, 97105-900 Santa Maria, RS, Brazil.

To investigate the effects of the ingestion of different amounts of Phalaris angusta, eight 6-8-month-old calves were assigned to four treatment groups. Group I calves were fed only $P$. angusta. Group II calves were fed a mixture of $75 \%$ of P. angusta and $25 \%$ of oat (Avena sativa) and ryegrass (Lolium multiflorum), whereas group III calves received a mixture of $50 \%$ of P.angusta and 50\% of oat and ryegrass. Group IV calves received only oat and ryegrass and served as controls. P. angusta was toxic for calves. One group I calf died 34 days after the beginning of the ingestion of the plant, and the other calves were euthanatized in extremis 18 to 32 days after de beginning of the experiment. The main clinical signs were locomotor disorders, generalized tremors, frequent falls, and convulsions. Gross findings were confined to the brain and consisted of focal areas of green-bluish discoloration in the thalamus, mesencephalon, and medulla oblongata. Microscopic lesions were characterized by the presence of a intracytoplasmic yellow-brown indole-like pigment in neurons from grossly affected areas. Ultrastructural changes consisted of swollen lysosomes containing membranous material with variable orientation and density. The amount of ingested $P$. angusta was not a determinant factor for the severity of clinical signs and lesions. The extension of gross and microscopic lesions was not directly related with the intensity of the clinical signs. P. angusta was exclusively neurotoxic and should be considered as a differential diagnosis in cases of neurological disease of cattle with clinical signs consistent with tremorgenic syndrome.
\end{abstract}

INDEX TERMS: Poisonous plants, CNS disease, Phalaris angusta, cattle.

RESUMO.- Para investigar os efeitos da ingestão de diferentes quantidades da planta Phalaris angusta em bovinos, oito bezerros, com idade variando entre 6-8 meses, foram divididos em 4 grupos com 2 animais cada. Os animais do grupo I receberam somente $P$. angusta na alimentação, enquanto que os animais do grupo II receberam P. angusta (75\%), aveia (Avena sativa) e azevém (Lolium multiflorum) (25\%). Os animais do grupo III receberam P. angusta (50\%), aveia e azevém (50\%) e os animais do grupo IV receberam somente aveia e azevém e serviram como controles. Todos os animais que ingeriram $P$.

\footnotetext{
${ }^{1}$ Aceito para publicação em 21 de dezembro de 1998.

${ }^{2}$ Depto Clínica e Patologia, Centro de Ciências Agroveterinárias, Universidade do Estado de Santa Catarina, Av. Luiz de Camões 2090, Lages, SC 88520 000 .

${ }^{3}$ Depto Patologia, Universidade Federal de Santa Maria, 97105-900 Santa Maria, RS.
}

angusta adoeceram. Um animal do grupo I morreu 34 dias após o início da ingestão da planta e os outros animais foram sacrificados, in extremis, em um período que variou de 18 a 32 dias após o início do experimento. Os principais sinais clínicos observados foram alterações de locomoção, tremores generalizados, quedas e crises convulsivas. Alterações macroscópicas foram observadas apenas no encéfalo e eram caracterizadas por focos de coloração verde-azulada no tálamo, mesencéfalo e medula oblonga. Microscopicamente observou-se pigmento granular marrom-amarelado no citoplasma de neurônios das regiões macroscopicamente afetadas. Alterações ultra-estruturais consistiram de lisossomos contendo material com densidade e orientação variáveis. A quantidade de $P$. angusta ingerida não foi um fator determinante na gravidade do quadro clínico, nem na intensidade das lesões observadas. A intensidade dos sinais clínicos também não teve uma relação direta com a severidade das lesões macro e microscópicas. Phalaris angusta demonstrou ter 
ação exclusivamente neurotóxica e deve ser considerada no diagnóstico diferencial em casos de animais com sinais clínicos de origem nervosa, consistentes com síndrome tremorgênica.

TERMOS DE INDEXAÇÃO: Plantas tóxicas, síndrome tremorgênica, Phalaris angusta, bovino.

\section{INTRODUÇÃO}

Surtos de intoxicação por plantas do gênero Phalaris (Gramineae) em bovinos e ovinos têm sido relatados em diversos países (McDonald 1942, Mendel et al. 1969, Ulvund 1985, Perdomo \& Paullier 1986, Odriozola et al. 1991). As espécies consideradas tóxicas incluem Phalaris aquatica, conhecida também como $P$. tuberosa (Bourke et al. 1987), P. arundinacea (Ulvund 1985), P. brachystachys (De Luco et al. 1990), $P$. canarinensis e P. paradoxa (Bourke 1994), P. caroliniana (Nicholson et al. 1989), P. minor (Mendel et al. 1969) e P. angusta (Odriozola et al. 1991). Duas formas clínicas estão associadas à intoxicação espontânea por Phalaris spp, uma forma nervosa e uma forma caracterizada por morte súbita (Bourke 1994). Alcalóides derivados de triptamina e beta-carbolina são incriminados nos surtos da forma nervosa (Bourke 1994). Tem sido sugerido que feniletilaminas (Bourke 1994) ou derivados da tiramina (Anderton et al. 1994) possam estar envolvidos na patogênese dos casos de morte súbita.

Há somente um relato da intoxicação por plantas do gênero Phalaris no Brasil, que descreve a ocorrência, em bovinos, da forma nervosa da toxicose por $P$. angusta (nomes comuns: aveia louca e aveia de sangue) em dois municípios do estado de Santa Catarina (Gava et al. 1999).

Devido ao aumento da utilização dessa gramínea na alimentação de ruminantes na região sul do Brasil, resolveu-se reproduzir a intoxicação por $P$. angusta em bovinos para caracterizar o quadro clínico, lesões macroscópicas e alterações histopatológicas e ultra-estruturais da toxicose, visando estabelecer condições para o diagnóstico da doença.

\section{MATERIAL E MÉTODOS}

Oito bezerros, com idades entre 6 e 8 meses, foram examinados clinicamente, pesados, identificados e divididos em 4 grupos contendo 2 animais cada. Os grupos receberam um tipo de alimentação diferenciada, constituída somente por ou aveia (Avena sativa) e azevém (Lolium multiflorum), ou por uma mistura de P. angusta, aveia e azevém, respeitando-se o consumo médio diário de forragem de bovinos (aprox. 10\% do peso vivo). Os bezerros do grupo I receberam somente $P$. angusta. Os animais do grupo II receberam uma dieta composta de P. angusta (75\%) complementada com aveia e azevém (25\%), enquanto que a dieta dos bezerros do grupo III consistiu de $P$. angusta (50\%) e de aveia e azevém (50\%). Os animais do grupo IV receberam apenas aveia e azevém e serviram como controles. A quantidade diária ingerida de $P$. angusta foi de $100 \mathrm{~g} / \mathrm{kg}$, $75 \mathrm{~g} / \mathrm{kg}$ e $50 \mathrm{~g} / \mathrm{kg}$ para os animais dos grupos I, II e III, respectivamente. Os bezerros foram mantidos em baias individuais de alvenaria e receberam água à vontade durante todo o experimento. $\mathrm{O}$ alimento foi fornecido no cocho duas a três vezes por dia, de acordo com o consumo de cada animal.

O exame clínico, onde foram avaliados batimentos cardíacos, frequência respiratória, movimentos ruminais e temperatura corporal, era repetido 2 vezes por dia durante todo o experimento. Atenção especial foi dada a sinais clínicos consistentes com alterações neurológicas indicativas da intoxicação por plantas do gênero Phalaris. Os bovinos eram soltos em piquetes, 3 a 4 vezes por dia, movimentados por 5 a 10 minutos, examinados clinicamente e colocados novamente nas baias.

A planta, P. angusta, foi identificada pelo Departamento de Botânica da Universidade Federal do Rio Grande do Sul, Porto Alegre, RS. A colheita foi realizada manualmente, uma ou duas vezes por semana, em propriedades rurais do município de Capinzal, SC. A planta foi acondicionada em sacos de pano e conservada sob refrigeração até a administração aos animais. Aveia e azevém foram colhidos em piquetes das mesmas propriedades rurais, onde essa pastagem havia sido estabelecida para alimentação de bovinos leiteiros. Todos os animais, com exceção de um bezerro do grupo I, que morreu espontaneamente, foram sacrificados in extremis e necropsiados.

Amostras de encéfalo, medindo $3 \times 3 \mathrm{~mm}$, foram colhidas de todos os bezerros, fixadas em glutaraldeído e encaminhadas para processamento de rotina para microscopia eletrônica de transmissão. $O$ restante do encéfalo e a medula espinhal foram fixados em formol a $10 \%$ e cortados transversalmente em seções de $0,5 \mathrm{~cm}$ de espessura. Fragmentos de vários órgãos foram coletados, fixados em formol a $10 \%$, e juntos com o sistema nervoso central, incluídos em parafina, seccionados a $5 \mu \mathrm{m}$ e corados com hematoxilina e eosina. Regiões do sistema nervoso central onde, na coloração de hematoxilina e eosina, foi observado o pigmento granular marrom-amarelado no citoplasma de neurônios, foram submetidas à coloração de ácido periódico de Schiff (PAS).

Os fragmentos de sistema nervoso central encaminhados para microscopia eletrônica de transmissão foram colhidos do tálamo (corpo geniculado lateral), mesencéfalo e cerebelo. Esses fragmentos foram fixados em solução de glutaraldeído $2 \%$, paraformaldeído $2 \%$ em tampão cacodilato de sódio $(0,03 \mathrm{M}$ e pH 7,4), pós-fixados em tetróxido de ósmio 1\%, desidratados em etanol e incluídos em resina epóxi. Os cortes semifinos foram corados com azul de toluidina. Desses cortes foram selecionadas regiões que foram duplamente contrastadas com acetato de uranila a $7 \%$ e citrato de chumbo a $2 \% \mathrm{e}$ examinados em microscópio eletrônico Zeiss EM10, operado a 80kv.

\section{RESULTADOS}

De todos os bovinos experimentais, apenas o bezerro $\mathrm{n}^{\circ} 2$ (grupo I) morreu expontaneamente, 34 dias após o início do experimento; os outros animais que adoeceram foram sacrificados, in extremis, em diferentes períodos após a ingestão da planta (Quadro 1). Os bezerros do grupo IV não adoeceram.

\section{Sinais clínicos}

Sinais clínicos de origem nervosa, consistentes com os descritos para a intoxicação espontânea por plantas do gênero Phalaris foram observados a partir do segundo dia após o início da ingestão de P. angusta (Quadro 2). Olhar atento e movimentos frequentes e ritmados das orelhas foram as primeiras manifestações clínicas observadas em todos os bovinos, independente da quantidade de $P$. angusta ingerida. Os terneiros assustavam-se facilmente frente a movimentos bruscos e ruídos. Esses sinais clínicos persistiram até o final do experimento, com agravamento do quadro, em todos os ani- 
Quadro 1. Intoxicação experimental por Phalaris angusta (Gramineae) em bovinos

\begin{tabular}{ccccc}
\hline $\begin{array}{c}\text { Bezerro } \\
\text { no. }\end{array}$ & Grupo & $\begin{array}{c}\text { Quantidade } \\
\text { da planta } \\
\text { administrada }\end{array}$ & $\begin{array}{c}\text { Morte espontânea (M) } \\
\text { ou sacrifício(S) } \\
(\mathrm{g} / \mathrm{kg})\end{array}$ & $\begin{array}{c}\text { Morte após o } \\
\text { início do expe- } \\
\text { rimento (dias) }\end{array}$ \\
\hline & & & & \\
1 & I & 100 & $\mathrm{~S}$ & 18 \\
2 & I & 100 & $\mathrm{M}$ & 34 \\
3 & II & 75 & $\mathrm{~S}$ & 32 \\
4 & II & 75 & $\mathrm{~S}$ & 32 \\
5 & III & 50 & $\mathrm{~S}$ & 23 \\
6 & III & 50 & $\mathrm{~S}$ & 23
\end{tabular}

a Os bezerros 7 e 8 (grupo IV) receberam apenas aveia e azevém e não adoeceram.

Quadro 2. Intoxicação experimental por Phalaris angusta (Gramineae) em bovinos. Início e duração dos sinais clínicos

\begin{tabular}{cccc}
\hline \multirow{2}{*}{$\begin{array}{c}\text { Bezerro } \\
\text { no. }\end{array}$} & $\begin{array}{c}\text { Dose administrada } \\
(\mathrm{g} / \mathrm{kg})\end{array}$ & \multicolumn{2}{c}{ Sinais clínicsos } \\
\cline { 3 - 4 } Início $^{\mathrm{a}}$ & Duração(dias) \\
1 & 100 & 5 & 13 \\
2 & 100 & 2 & 32 \\
3 & 75 & 5 & 28 \\
4 & 75 & 12 & 20 \\
5 & 50 & 7 & 23 \\
6 & 50 & 8 & 15
\end{tabular}

a Dias após o início da ingestão da planta.

mais, exceto no bovino $\mathrm{n}^{\circ} 3$ que apresentou um quadro mais leve.

Tremores musculares generalizados e alterações de locomoção foram observados em todos os amimais. $O$ bezerro $\mathrm{n}^{\circ} 2$ mostrou grande dificuldade para beber água devido à intensidade dos tremores. As alterações de locomoção caracterizaram-se inicialmente por andar rígido, seguido por severa hipermetria, andar em marcha, movimentos simultâneos dos membros posteriores e, às vezes, cruzamento dos membros anteriores ao andar. Essas alterações e os tremores musculares generalizados eram exacerbados pelo exercício forçado. Nesse período, os animais caíam sobre a parte posterior do corpo, ou em decúbito lateral. Quando conseguiam firmar os membros anteriores, permaneciam longo tempo apoiando-se nos joelhos, com tremores musculares acentuados nos membros posteriores, cabeça e pescoço. Dois bezerros ( ${ }^{\text {os }} 2$ e 5$)$ apresentaram vários episódios de ataque epileptiforme, com duração de, no máximo, 30 segundos, acompanhados por tremores e contrações tetânicas dos membros anteriores e posteriores, nistagmo e dificuldade respiratória.

Alterações na apreensão e mastigação do alimento e presença transitória de fezes pastosas ou amolecidas foram também observadas. Apesar dos sinais clínicos acentuados, em nenhum momento os animais deixaram de demonstrar interesse pela planta.

\section{Achados de necropsia}

As alterações macroscópicas encontradas, compatíveis com as descritas na intoxicação espontânea por Phalaris spp,

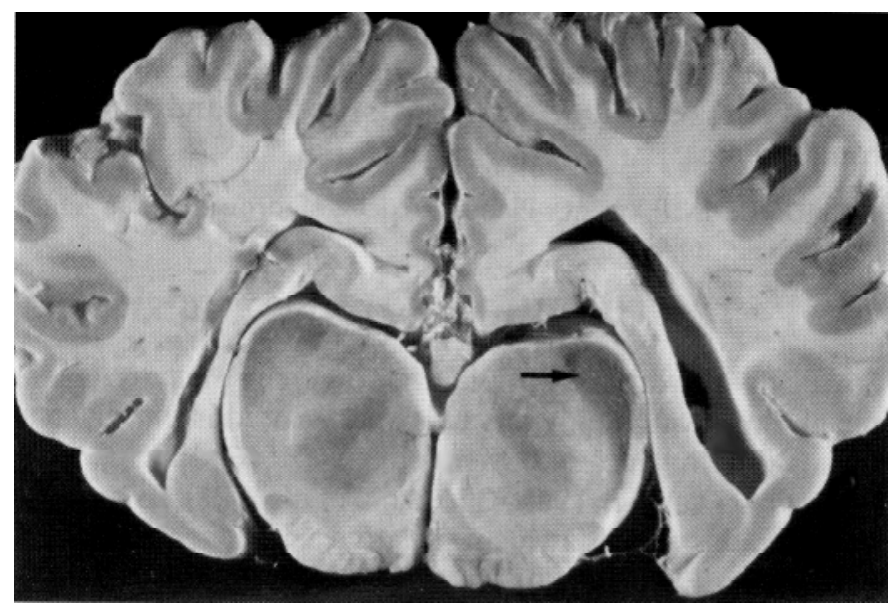

Fig. 1. Corte transversal do encéfalo, fixado em formol, com coloração escura bem demarcada no corpo geniculado lateral do tálamo (seta), na intoxicação experimental por Phalaris angusta em bovino $\left(n^{\circ} 1\right)$.

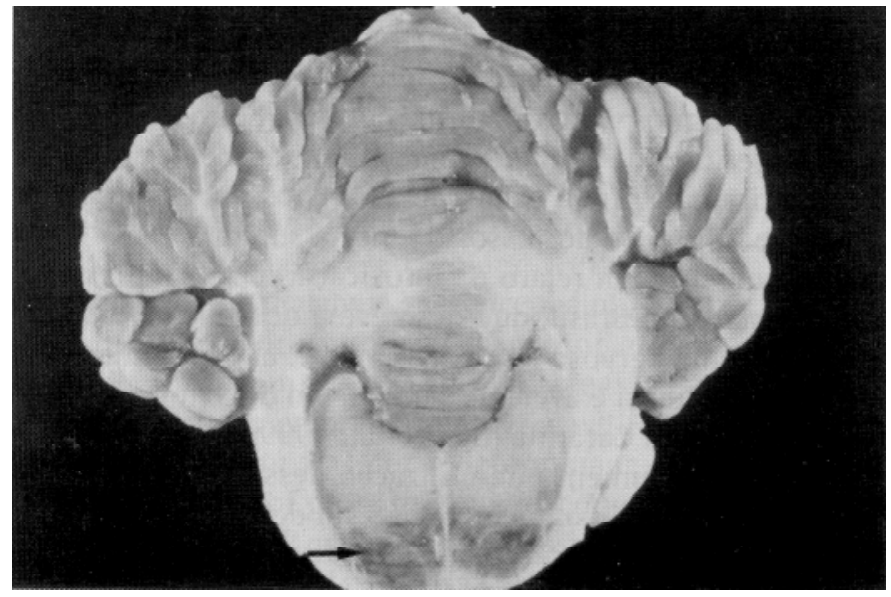

Fig. 2. Corte transversal do encéfalo, fixado em formol, com coloração escura intensa na ponte (seta), na intoxicação experimental por $P$. angusta em bovino $\left(\mathrm{n}^{\circ} 2\right)$.

estavam restritas ao encéfalo e caracterizavam-se pela presença de coloração verde-azulada em determinadas regiões do tálamo e mesencéfalo, com distribuição bilateral e simétrica. As seções transversais de encéfalo apresentavam, no início do tálamo, uma coloração verde-azulada discreta. Um animal ( $\left.n^{\circ} 4\right)$ apresentou pigmentação mais intensa nessa localização. Em segmentos adjacentes ao tálamo havia um aumento de intensidade da coloração em três animais ( ${ }^{o s} 2$, 4 e 6). Nesses bezerros, as regiões mais afetadas eram os corpos geniculados lateral e medial e a região pulvinar. Outros núcleos talâmicos como os núcleos laterais (dorsal e ventral), medial e ventral também estavam afetados, embora numa intensidade menor. Nos outros três animais ( $n^{\text {os }} 1,3$ e 5), a intensidade da coloração variou de leve a moderada. A região em que melhor observou-se a alteração correspondia ao corpo geniculado lateral e medial (Fig. 1). Nos seis bovinos, a coloração tornou-se menos intensa a medida em que se prosseguiam os cortes seriados, ao longo do tronco cerebral. No mesencéfalo, a alteração de coloração foi observada com 


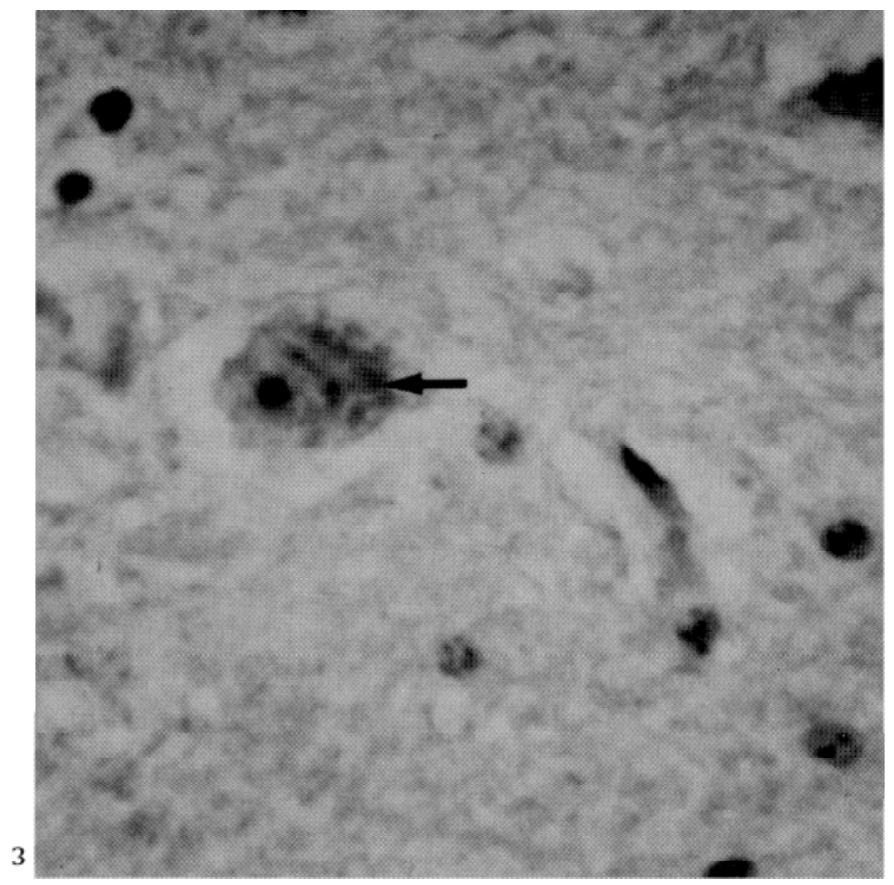

maior frequência no núcleo do nervo troclear, substância nigra, fascículo longitudinal medial e lemnisco lateral.

Na medula oblonga a alteração foi observada nos núcleos da ponte, tratos corticobulbar e córtico-espinhal, corpo trapezóide e lemnisco medial, em intensidade leve a moderada (Fig. 2). Seções realizadas caudalmente à medula oblonga e na medula espinhal não apresentaram alterações macroscópicas.

Achados microscópicos e ultra-estruturais

À microscopia óptica observou-se a presença de um pigmento finamente granular, marrom-amarelado, no citoplasma de neurônios (Fig. 3). Essa alteração ocorreu em todos os animais. Os bezerros do grupo I apresentavam alterações em neurônios do tálamo, mesencéfalo e medula oblonga. $\mathrm{O}$ tálamo era mais intensamente afetado, enquanto que no mesencéfalo e medula oblonga a presença do pigmento era mais discreta. Nos bovinos dos grupos II e III, o pigmento foi visualizado numa distribuição semelhante à do grupo I, embora ocorrendo de forma levemente menos intensa. $\mathrm{O}$ pigmento não foi detectado em seções do encéfalo localizadas rostralmente ao tálamo e caudalmente à medula oblonga, bem como nas seções da medula espinhal. Além da presença do pigmento, em alguns animais foi observado discreto infiltrado inflamatório mononuclear perivascular.

Nos bovinos intoxicados experimentalmente os grânulos intracitoplasmáticos não demostraram-se positivos para ácido periódico de Schiff (PAS).

Nos cortes semifinos corados com azul de toluidina foi observado, no citoplasma dos neurônios do tálamo e mesencéfalo, um pigmento finamente granular, que na microscopia eletrônica de transmissão foi caracterizado como perfis de membranas de orientação e densidades diferentes, no interior de lisossomos (Fig. 4).

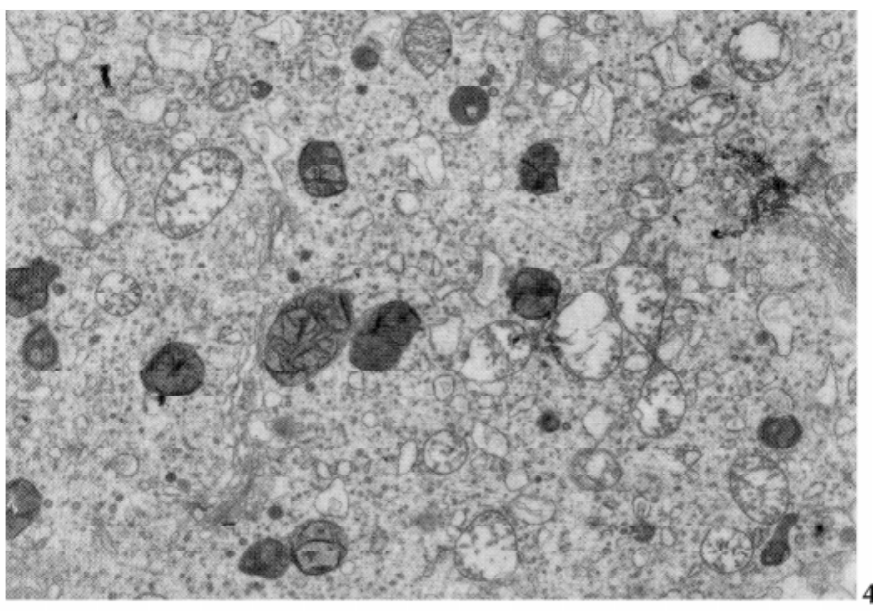

Fig. 3. Intoxicação experimental por P. angusta em bovinos ( $\left.\mathrm{n}^{\mathrm{o}} 1\right)$. Corte do tálamo. Pigmento granular intracitoplasmático (seta) em neurônio. HE, obj 40.

Fig. 4. Intoxicação experimental por $P$. angusta em bovino $\left(\mathrm{n}^{\circ} 2\right)$. Neurônio do corpo geniculado lateral. Lisossomos com densidade aumentada contendo perfis de membranas. $12.000 \mathrm{x}$.

\section{DISCUSSÃO}

Phalaris angusta demonstrou-se tóxica para todos os bovinos que a ingeriram nas proporções de $100 \%, 75 \%$ e $50 \%$ da dieta. Esse resultado está em acordo com relatos de intoxicação natural em bovinos por P. angusta (Odriozola et al. 1991), $P$. caroliniana (Nicholson et al. 1989) e P. aquatica (Kennedy et al. 1986), quando formavam a pastagem dominante, e na intoxicação natural por $P$. minor quando esta constituía aproximadamente 50\% da pastagem (Mendel et al. 1969). Os surtos naturais descritos em bovinos e ovinos estão relacionados com pastagens consorciadas de Phalaris sp e leguminosas, com predomínio de Phalaris sp. Normalmente as pastagens consorciadas de Phalaris sp não apresentam problemas quando em condições normais de manejo. Embora fatores como fase de crescimento da planta, estiagem, sombreamento, temperatura e suplementação de nitrogênio possam interferir com o nível de alcalóides triptamínicos na planta e, em consequência, com o grau da intoxicação (Baal \& Hoveland 1978), neste experimento as condições de plantio e colheita de $P$. angusta não variaram. As amostras colhidas e conservadas em refrigeração estavam em fase de crescimento (50-60 cm de altura).

O quadro clínico-patológico apresentado pelos animais foi característico da síndrome nervosa ("phalaris staggers") que acomete tanto bovinos, quanto ovinos, descrita por Bourke (1994). A síndrome de morte súbita, que pode se apresentar numa forma cardíaca ou de polioencefalomalácia (Bourke et al. 1990, Bourke 1994), não foi observada em nenhum dos animais do experimento.

$O$ período em que apareceram os primeiros sinais clínicos variou entre 2 e 12 dias após o início da ingestão de $P$. angusta. $\mathrm{O}$ animal $\left(\mathrm{n}^{\circ} 2\right)$ que mais precocemente demonstrou sinais clínicos recebia uma dieta composta somente de $P$. 
angusta, enquanto que o bovino ( $\left.\mathrm{n}^{\circ} 4\right)$, que demorou mais tempo para apresentar os sinais clínicos, recebia $75 \%$ de $P$. angusta na dieta. Os animais que foram sacrificados apresentaram sinais clínicos nervosos acentuados, durante um período que variou de 13 a 28 dias, enquanto que o bovino que morreu, permaneceu doente durante 32 dias. No caso de bovinos intoxicados naturalmente, os sinais clínicos foram observados em períodos diversos, variando entre 3 e 5 dias (Odriozola et al. 1991), 10 e 12 dias (Mendel et al. 1969, Kennedy et al. 1986) ou aproximadamente 45 dias após o contato com a planta (Nicholson et al. 1989). Nos casos naturais que ocorreram no Brasil (Gava et al. 1999) os bovinos apresentaram sinais clínicos nervosos em aproximadamente 10-20 dias após serem colocados na pastagem. Os animais recuperaram-se gradualmente quando foram retirados da pastagem. $O$ desenvolvimento de sinais clínicos em um curto período, após o início da ingestão da planta, pode estar relacionado com a fase de crescimento em que P. angusta foi colhida e administrada aos animais. Gava et al. (1999) descreveram que, quando plantas mais velhas foram administradas aos animais, o desenvolvimento dos sinais clínicos foi mais tardio e de forma mais branda.

Olhar atento e movimentos frequentes e ritmados das orelhas foram os primeiros sinais clínicos apresentados pelos bovinos, juntamente com a característica de se assustarem facilmente frente a movimentos bruscos e ruídos. Essas características específicas não são descritas em casos de intoxicação natural em bovinos, com exceção dos casos observados por Gava et al. (1999). Apesar disso é relatada a ocorrência de hiperexcitabilidade como uma condição comum a todos os casos naturais (Kennedy et al. 1986, Odriozola et al. 1991, Bourke 1994). Em ovinos intoxicados natural e experimentalmente é descrito o aparecimento de contrações rápidas da orelha, além de animais que se assustam com facilidade (Bourke et al. 1990, Van Halderen et al. 1990).

Tremores musculares generalizados e alterações de locomoção que ocorreram em todos os animais também são descritos em casos naturais em bovinos (Mendel et al. 1969, Kennedy et al. 1986, Odriozola et al. 1991, Gava et al. 1999) e ovinos (Bourke et al. 1990, De Luco et al. 1991, Odriozola et al. 1991). Os tremores musculares intensos dificultaram a ingestão de água em um animal $\left(n^{\circ} 2\right)$. A dificuldade para ingestão de água e alimentos também é relatada em bovinos, estando relacionada a movimentos incoordenados da língua (Mendel et al. 1969, Nicholson et al. 1989). Bourke (1994) descreve que a ocorrência de distúrbios de locomoção em bovinos intoxicados por Phalaris spp. tende a ser mais limitada do que em ovinos e apresentam leve paresia de membros torácicos e leve incoordenação motora. Neste experimento, alterações de locomoção acentuadas foram observadas em todos os animais, incluindo movimentos simultâneos dos membros posteriores ao caminhar. Alteração similar foi descrita apenas em ovinos. (East \& Higgins 1988, Odriozola et al. 1991).

O desenvolvimento de convulsões (ataques epileptiformes) foi um sinal que acometeu dois animais ( $n^{\text {os }} 2$ e 5 ) que recebiam $100 \%$ e $50 \%$ de $P$. angusta na dieta, respectivamente. Os ataques duravam aproximadamente 30 segundos, com posterior recuperação. A ocorrência de convulsões é descrita em ovinos (Nicholson et al. 1989, Bourke et al. 1990) e bovinos (Gava et al. 1999).

No transcorrer do experimento, todos os bovinos mantiveram interesse pela planta. Esta característica difere de outras situações descritas anteriormente, onde é relatada a ocorrência de inapetência em bovinos intoxicados naturalmente (Bourke 1994).

O bovino $\mathrm{n}^{\mathrm{O}} 2$ morreu 34 dias após o início do experimento, com sinais clínicos nervosos bastante acentuados, permanecendo em decúbito por aproximadamente 36 horas. A morte de animais acometidos pela forma nervosa é descrita em bovinos e ovinos (Kennedy et al. 1986, Nicholson et al. 1989, Odriozola et al. 1991), ocorrendo em aproximadamente uma semana após a ingestão da planta ou quando ingerida por períodos maiores. 0 mecanismo que levou os animais à morte não foi determinado. Bourke (1994) sugeriu que a morte provavelmente ocorra devido à ação dos alcalóides derivados da triptamina sobre o sistema nervoso central.

A variação observada no quadro clínico, em relação aos casos da intoxicação natural em bovinos e ovinos, pode ser atribuída, pelo menos parcialmente, ao fato de ocorrer grande variabilidade no conteúdo das substâncias químicas indicadas como responsáveis pela intoxicação. Diferenças observadas na severidade e reversibilidade dos sinais clínicos em surtos da intoxicação refletem diferenças entre espécies e na quantidade de alcalóides derivados da triptamina e beta-carbolina presentes na planta (Bourke 1994). Pastagens de Phalaris spp com níveis baixos de cobalto são implicadas como sendo responsáveis pelo aparecimento da síndrome nervosa. Tem sido proposto que o cobalto é importante para a degradação dos alcalóides tóxicos pela flora ruminal. Assim, se cobalto é encontrado em quantidades suficientes nas pastagens compostas de Phalaris spp a microflora ruminal converte os alcalóides tóxicos em substâncias não-tóxicas e a intoxicação não ocorre (Bourke 1994).

As alterações de necropsia encontradas nos bovinos, caracerizadas por coloração verde-azulada em determinadas regiões do encéfalo, variaram de intensidade de um animal para outro e num mesmo animal, levando-se em conta as regiões afetadas. Embora essa variação de intensidade tenha sido observada, não foi determinada uma relação direta entre o grau de pigmentação no encéfalo e a quantidade de $P$. angusta ingerida. A região onde o pigmento foi encontrado em maior quantidade correspondia ao corpo geniculado lateral, no tálamo, o que foi observado também por Lean et al. (1989), Odriozola et al. (1991) e De Luco et al. (1991). Outros núcleos talâmicos como corpo geniculado medial, pulvinar, núcleos laterais, medial e ventral também apresentavam alteração de coloração. A presença do pigmento na medula espinhal, relatada por outros (East \& Higgins 1988), não foi observada em nenhum animal. Do mesmo modo, nenhum bovino intoxicado experimentalmente demonstrou uma alteração de coloração ou qualquer outra alteração macroscópica, em outros órgãos, além do encéfalo.

As alterações microscópicas foram as características da 
intoxicação por Phalaris spp descritas anteriormente. $\mathrm{O}$ pigmento granular marrom-amarelado, semelhante ao indol, observado no citoplasma de alguns neurônios, foi um achado constante nos animais que ingeriram $P$. angusta. Regiões onde macroscopicamente observou-se uma pigmentação verde-azulada apresentavam corpos neuronais contendo o pigmento granular. A região onde o pigmento foi encontrado em maior quantidade correspondia ao corpo geniculado, no tálamo. Nas outras regiões, neurônios ou grupos de neurônios apresentavam leve granulação marrom-amarelada no citoplasma. Embora a natureza do pigmento intracitoplasmático encontrado em neurônios seja desconhecida, é incerto que esse pigmento seja responsável pela sintomatologia observada em animais intoxicados. Tem sido proposto que as alterações morfológicas não são um pré-requisito para o desenvolvimento dos sinais clínicos, uma vez que, experimentalmente, esses podem ser produzidos após a administração endovenosa dos derivados da triptamina, antes do desenvolvimento de qualquer alteração morfológica (Bourke 1994). Da mesma forma, em casos naturais foram observados sinais clínicos que não foram acompanhados de alterações morfológicas evidentes (Bourke et al. 1990). Tem sido sugerido que os sinais clínicos observados na síndrome nervosa talvez sejam de origem bioquímica e não estrutural (Bourke 1994). Os alcalóides derivados da triptamina inicialmente agiriam em receptores serotonérgicos, localizados tanto em dendritos quanto em axônios, sendo responsáveis pelos sinais clínicos nervosos observados (Bourke et al. 1990).

Discreto infiltrado mononuclear perivascular foi ocasionalmente observado em alguns cortes. Embora esse achado seja similar ao descrito na síndrome nervosa por East \& Higgins (1988), Lean et al. (1989) e De Luco et al. (1991), infiltrados inflamatórios perivasculares podem ser estimulados por processos desmielinizantes agudos (Jubb \& Huxtable 1993), o que não foi observado nos animais em experimentação. Como a condição que acomete os animais desse experimento não é de natureza infecciosa ou inflamatória, a presença de infiltrado inflamatório mononuclear perivascular discreto no encéfalo de alguns animais pode ser um achado incidental e sem relação com o quadro desenvolvido pelos animais.

Na microscopia eletrônica de transmissão, os neurônios, que na microscopia óptica continham o pigmento característico marrom-amarelado, apresentavam, como característica mais marcante, numerosos lisossomos tumefeitos. Estruturas laminares presentes no interior dos lisossomos, descritas como perfis de membrana, apresentavam orientação e densidade diferentes. Esse achado diferiu dos casos naturais nos quais é descrita a presença de membranas lamelares concêntricas únicas ou múltiplas no interior de lisossomos (East et al. 1988, De Luco et al. 1991). Autolisossomos ou vacúolos autofágicos podem ser visualizados como vesículas contendo estruturas envoltas por duplas membranas, que podem ser resultado do sequestro de estruturas celulares membranosas. Freqüientemente encontram-se autolisossomos em tecidos normais, indicando um mecanismo normal em células antigas ou causado por vários agentes, indicando uma condi- ção de injúria intracelular, focal e subletal (Ghadially 1988). Os lisossomos encontrados nos animais que ingeriram $P$. angusta podem representar autolisossomos. No entanto, o significado da variação no aspecto morfológico dos lisossomos não foi determinado. Se a forma de armazenamen-to do pigmento semelhante ao indol está relacionada à espécie de Phalaris, ao tempo de ingestão da planta ou à quantidade dos princípios tóxicos ingeridos ou ainda se os princípios tóxicos presentes em $P$. angusta induzem à formação de autolisossomos permanece por ser esclarecido.

Nas condições deste experimento, $P$. angusta causou a forma nervosa da toxicose e portanto deve ser levada em consideração no diagnóstico diferencial de outras condições que cursam com sintomatologia nervosa, como a intoxicação por Cynodon dactylon, Lolium perenne, Solanum fastigiatum var. fastigiatum e Claviceps paspali.

Agradecimentos.- Ao Prof. Aldo Gava, da Universidade do Estado de Santa Catarina, pela valiosa colaboração no trabalho de experimentação e ao Dr. Severo Salles de Barros pela preparação das fotografias de microscopia eletrônica.

\section{REFERÊNCIAS}

Anderton N., Cockrum P.A., Walker D.W. \& Edgar J.A. 1994. Identification of a toxin suspected of causing death in livestock grazing Phalaris pastures, p. 269-274. In: Colegate S.M. \& Dorling P.R. (ed.) Plant-associated Toxins. Agricultural, phytochemical and ecological aspects. CAB International, Farnham Royal, Slough, UK.

Baal D.M. \& Hoveland C.S. 1978. Alkaloid levels in Phalaris aquatica L. as affected by environment. Agronomy Journal 70:977-981.

Bourke C. A., Carrigan M.J. \& Dixon R.J. 1990. The pathogenesis of the nervous syndrome of Phalaris aquatica toxicity in sheep. Aust. Vet. J. 67(10):356358.

Bourke C. A., Carrigan M. J., Seaman J. T. \& Evers J. V. 1987. Delayed development of clinical signs in sheep affected by Phalaris aquatica staggers. Aust. Vet. J. 64(1):31-32.

Bourke C. A. 1994. The clinico-toxicological differentiation of Phalaris spp. toxicity syndromes in ruminants, p. 523-528. In: Colegate S.M. \& Dorling P.R. (ed.) Plant-associated Toxins. Agricultural, phytochemical and ecological aspects. CAB International, Farnham Royal, Slough, UK.

De Luco F. D., García Marín J. F., Badiola J. J., Luján L. \& Pérez V. 1991. Intoxicación ovina debido al consumo de falaris (Phalaris brachystachys). Med. Vet., B. Aires, 8(3):167-175.

East N. E. \& Higgins R. J. 1988. Canary grass (Phalaris sp.) toxicosis in sheep in California. J. Am. Vet. Med. Assoc. 192(5):667-669.

Gava A., Sousa R. S., Deus M. S., Pilati C., Cristani J., Mori A. M. \& Neves D. S. 1999. como causa de enfermidade neurológica em bovinos no Estado de Santa Catarina. Pesq. Vet. Bras. (Em publicação)

Ghadially F. N. 1988. Ultrastructural Pathology of the Cell and Matrix. 3rd ed. Butterworths, London, p. 589-765.

Jubb K. V. F. \& Huxtable C. R. 1993. The nervous system, p. 267-439. In: Jubb K. V. F., Kennedy P. C. \& Palmer N. (ed.) Pathology of Domestic Animals. 4th ed. Academic Press, San Diego. 780p.

Kennedy D. J., Cregan P. D., Glastonbury J. R. W., Golland D. T. \& Day D. G. 1986. Poisoning of cattle grazing a low-alkaloid cultivar of Phalaris aquatica, Sirolan. Aust. Vet. J. 63(3):88-89.

Lean I. J., Anderson M., Kerfoot M.G. \& Marten, G. C. 1989. Tryptamine alkaloid toxicosis in feedlot sheep. J. Am. Vet. Med. Assoc. 195(6):768-771.

McDonald I. W. 1942. A "staggers" syndrome in sheep and cattle associated with grazing on Phalaris tuberosa. Aust. Vet. J. 18:182-188.

Mendel V. E., Crenshaw G. L., Baker N. F. \& Muniz R. 1969. Staggers in pastured cattle. J. Am. Vet. Med. Assoc. 154(7):769-772. 
Nicholson S. S., Olcott B. M., Usenick E. A., Casey H. W., Brown C. C., Urbatsch L. E., Turquist S. E. \& Moore S. C. 1989. Delayed Phalaris grass toxicosis in sheep and cattle. J. Am. Vet. Med. Assoc. 195(3):345-346.

Odriozola E., Campero C., Lopez T., Marin R., Casaro G. \& Andrada M. 1991. Neuropathological effects and deaths of cattle and sheep in Argentina from Phalaris angusta. Vet. Human Toxicol. 33(5):465-467.

Perdomo E. \& Paullier C. 1986. Enfermedades que afectan el Sistema Nervioso
Central, p. 143-172. In: Enfermedades de los Lanares. Hemisferio Sur, Montevideo.

Ulvund M. J. 1985. Chronic poisoning in a lamb grazing Phalaris arundinacea. Acta. Vet. Scand. 26:286-288.

Van Halderen A., Green J. R. \& Schneider D. J. 1990. An outbreak of suspected Phalaris staggers in sheep in the Western Cape Province. J. South Afr. Vet. Assoc. 61(1):39-40. 